\title{
Qualidade de lagostas armazenadas em diferentes condições de temperatura e embalagem
}

\section{Quality of lobsters stored under different conditions of temperature and packaging}

Luciana Façanha Marques $^{1 *}$ (1), Mario Eduardo Moreira Rangel Cavalcanti Mata ${ }^{1}$, Maria Elita Martins Duarte ${ }^{1}$, Marlene Nunes Damaceno ${ }^{2}$

${ }^{1}$ Universidade Federal de Campina Grande (UFCG), Centro de Tecnologia e Recursos Naturais, Unidade Acadêmica de Engenharia Agrícola, Campina Grande/PB - Brasil

${ }^{2}$ Instituto Federal de Educação, Ciência e Tecnologia do Ceará (IFCE), Campus Limoeiro do Norte, Limoeiro do Norte/CE - Brasil

*Corresponding Author: Luciana Façanha Marques, Universidade Federal de Campina Grande (UFCG), Centro de Tecnologia e Recursos Naturais, Unidade Acadêmica de Engenharia Agrícola, Av. Aprígio Veloso, 882, Caixa Postal: 10078, CEP: 58429-970, Campina Grande/PB - Brasil, e-mail: lucianamarques_ce@yahoo.com.br

Cite as: Marques, L. F., Mata, M. E. M. R. C., Duarte, M. E. M., \& Damaceno, M. N. (2019). Quality of lobsters stored under different conditions of temperature and packaging. Brazilian Journal of Food Technology, 22, e2016031. https://doi.org/10.1590/1981-6723.03116

\begin{abstract}
Resumo
A lagosta é uma espécie marinha de grande importância em muitos países. As mudanças bioquímicas e microbiológicas que ocorrem após a captura determinam sua qualidade e vida útil. Objetivou-se, neste trabalho, estudar o efeito da temperatura de armazenamento sob congelamento $\left(-30^{\circ} \mathrm{C},-80^{\circ} \mathrm{C}\right.$ e $\left.-150{ }^{\circ} \mathrm{C}\right)$, do tipo de embalagem (polietileno de baixa densidade - PEBD, com vácuo e sem vácuo) e do tempo de armazenamento $(0,60,120,180,240,300$ e 360 dias) sobre as características físicas de cor (luminosidade, intensidade de vermelho e amarelo) e químicas (proteínas e lipídeos) da lagosta. Durante o armazenamento, os parâmetros físicos luminosidade e intensidade de vermelho aumentaram, a intensidade de amarelo diminuiu, os teores de proteína diminuíram, porém para lipídeos não houve diferença significativa. Pode-se concluir que as temperaturas de armazenamento estudadas e a presença ou ausência de vácuo nas embalagensforam eficientes na manutenção das características físicas e químicas das caudas das lagostas armazenadas.
\end{abstract}

Palavras-chave: Panulirus argus; Conservação; Embalagem a vácuo; Congelamento.

\begin{abstract}
Lobster is a marine species of great importance in many countries and the biochemical and microbiological changes that occur after capture determine its quality and shelf life. The objective of this work was to study the effect of the storage temperature $\left(-30{ }^{\circ} \mathrm{C},-80^{\circ} \mathrm{C}\right.$ and $-150^{\circ} \mathrm{C}$ ), the type of packaging (low density polyethylene - LDPE with and without vacuum) and the storage time $(0,60,120,180,240,300$ and 360 days) on the colour (luminosity, red and yellow intensity) and chemical characteristics (proteins and lipids) of the lobster. During storage the physical parameters of luminosity and red intensity increased, the yellow intensity decreased, the protein levels decreased
\end{abstract}


and there was no significant difference in the lipid content. It was concluded that the freezing temperatures studied and both the presence and absence of vacuum in the polyethylene bags during storage were efficient in maintaining the physical and chemical characteristics of the lobster tails.

Keywords: Panulirus argus; Preservation; Vacuum package; Freezing.

\section{Introdução}

A lagosta é um produto pesqueiro de elevado valor comercial para a Região Nordeste do Brasil, tendo em vista a exportação para mercados com elevado poder aquisitivo (Igarashi, 2007).

Segundo dados da FAO, dentre os grandes grupos que vêm sendo capturados mundialmente, os peixes se destacam em quantidade, enquanto que os crustáceos são, de forma geral, os mais valiosos economicamente. Os principais destinos da lagosta brasileira foram Japão, França, Bélgica, Países Baixos e Canadá (Food and Agriculture Organization of the United Nations, 2014).

A pesca de lagostas na costa brasileira é uma das atividades pesqueiras de maior importância social e econômica, especialmente para os municípios da faixa litorânea da Região Nordeste. É uma atividade voltada, basicamente, para o mercado externo. A qualidade sanitária da lagosta exportada para a Europa pelo Brasil tem sido fator determinante no estabelecimento de barreiras à exportação do pescado brasileiro. $\mathrm{O}$ regulamento adotado pela União Europeia exige certificados de testes laboratoriais para assegurar aos importadores produtos dentro dos padrões exigidos e que sejam sinônimos de segurança alimentar, de acordo com a Secretaria Especial de Aquicultura e Pesca (Brasil, 2013).

Por ser um alimento de fácil decomposição, exige-se cuidado especial relacionado à conservação pelo frio, visto que, normalmente, a lagosta brasileira é comercializada na forma de caudas resfriadas ou conservadas em gelo.

Tendo em vista a falta de informações sobre a qualidade de caudas de lagosta durante armazenamento, objetivou-se, neste trabalho, avaliar o efeito de diferentes temperaturas de armazenamento sob congelamento e de embalagens com e sem vácuo sobre características físicas (cor) e químicas (proteínas e lipídeos) da lagosta.

\section{Material e métodos}

\subsection{Beneficiamento da matéria-prima}

Foram utilizadas lagostas capturadas no litoral do Rio Grande do Norte, da espécie lagosta vermelha, Panulirus argus. As mesmas foram levadas a um frigorífico, no qual foram inspecionadas, classificadas, mortas por choque térmico à temperatura de $0{ }^{\circ} \mathrm{C}$, descascadas e lavadas com água gelada (aproximadamente $10{ }^{\circ} \mathrm{C}$ ) corrente e clorada (5 ppm). Em seguida, as lagostas foram acondicionadas em caixas térmicas com gelo, formato em escamas, e transportadas para o Laboratório de Armazenamento e Processamento de Produtos Agrícolas (LAPPA) da Unidade Acadêmica de Engenharia Agrícola (UAEA), do Centro de Tecnologia e Recursos Naturais (CTRN) da Universidade Federal de Campina Grande (UFCG), Campus Campina Grande, Paraíba.

Após a chegada ao laboratório, as mesmas foram imersas em recipientes contendo uma mistura de água, gelo e metabissulfito de sódio, na proporção 20 litros de água, $10 \mathrm{~kg}$ de gelo e $20 \mathrm{~g}$ de metabissulfito de sódio, durante 40 minutos. Essa etapa visa à inibição do aparecimento de manchas pretas (melanose), fator indesejável e que acontece espontaneamente em crustáceos. Uma vez concluída a lavagem, as lagostas foram classificadas individualmente pelo peso, verificado por meio de balanças eletrônicas digitais, marca Edutec 
e modelo JK-EB-3200G, sendo acondicionadas em porções de aproximadamente 300 gramas em embalagens plásticas de polietileno de baixa densidade $(16 \mathrm{~cm} \times 23 \mathrm{~cm})$ com ou sem vácuo (seladora modelo DZ-260). Posteriormente, as caudas das lagostas embaladas foram armazenadas em freezer convencional $\left(-30^{\circ} \mathrm{C}\right)$, em balcão semicriogênico $\left(-80^{\circ} \mathrm{C}\right)$ e em balcão criogênico $\left(-150^{\circ} \mathrm{C}\right)$ modelo DW-150L 100 , marca Arauto, pertencentes ao setor de criogenia da Universidade Federal de Campina Grande-PB.

\subsection{Análises físicas e químicas da lagosta}

A cor foi determinada por leitura direta do produto, utilizando-se espectrofotômetro mini Scan Hunter Lab XEPlus, com sistema de cor Cielab. Os parâmetros determinados foram: L*, que representa a luminosidade, transição do branco (0) para o preto (100); $a^{*}$, que representa a transição da cor verde (-a*) para a cor vermelha $\left(+a^{*}\right)$, e b*, a transição da cor azul $\left(-b^{*}\right)$ para a cor amarela $\left(+b^{*}\right)$. Para a realização das leituras, as amostras de lagostas cruas foram cortadas e acondicionadas em recipientes cilíndricos plásticos de cor preta. Foram realizadas três leituras em diferentes pontos de cada amostra.

As análises químicas realizadas foram de proteína e lipídeos, segundo metodologias descritas pelo Instituto Adolfo Lutz (2008).

\subsection{Análise estatística}

Os resultados das análises químicas e físicas foram avaliados com o programa computacional Assistat versão 7.6 Beta (Silva \& Azevedo, 2009), com delineamento inteiramente casualizado, disposto em esquema fatorial $7 \times 2$ (tempo e embalagem), com três repetições para as três temperaturas estudadas $\left(-30{ }^{\circ} \mathrm{C},-80{ }^{\circ} \mathrm{C}\right.$ e $-150^{\circ} \mathrm{C}$ ). A comparação entre as médias foi realizada por meio do Teste de Tukey a $5 \%$ de probabilidade.

\section{Resultados e discussão}

Os valores dos parâmetros de luminosidade $\left(\mathrm{L}^{*}\right)$, intensidade de vermelho $\left(\mathrm{a}^{*}\right)$ e intensidade de amarelo $(* \mathrm{~b})$, apresentados nas Tabelas 1, 2 e 3, respectivamente, para as caudas das lagostas armazenadas sob diferentes temperaturas de congelamento, em embalagens com vácuo e sem vácuo, mostraram efeito significativo a $5 \%$ de probabilidade pelo Teste $\mathrm{F}$, para as fontes de variação tempo de armazenamento e embalagens utilizadas, e para a interação entre os dois fatores.

Tabela 1. Valores médios do parâmetro de luminosidade das caudas de lagosta embaladas com vácuo e sem vácuo, armazenadas a $-30{ }^{\circ} \mathrm{C},-80{ }^{\circ} \mathrm{C}$ e $-150{ }^{\circ} \mathrm{C}$, durante 360 dias.

\begin{tabular}{cccc}
\hline & & Luminosidade $\left(\mathbf{L}^{*}\right)$ \\
\hline \multirow{2}{*}{ Temperatura } & $\begin{array}{c}\text { Tempo de } \\
\text { Armazenamento } \\
\text { (dias) }\end{array}$ & Sem vácuo & Embalagem \\
\cline { 2 - 3 } & 0 & $52,03 \pm 0,50 \mathrm{dA}$ & Com vácuo \\
& 60 & $52,59 \pm 0,51 \mathrm{dA}$ & $52,03 \pm 0,50 \mathrm{dA}$ \\
$-30{ }^{\circ} \mathrm{C}$ & 120 & $53,54 \pm 0,23 \mathrm{cdA}$ & $52,31 \pm 0,34 \mathrm{dA}$ \\
& 180 & $55,29 \pm 0,25 \mathrm{cA}$ & $53,09 \pm 0,32 \mathrm{cdA}$ \\
& 240 & $57,44 \pm 1,32 \mathrm{bA}$ & $54,91 \pm 0,55 \mathrm{bcA}$ \\
& 300 & $58,55 \pm 1,01 \mathrm{bA}$ & $56,73 \pm 1,42 \mathrm{bA}$ \\
\hline
\end{tabular}


Tabela 1. Continuação...

\begin{tabular}{cccc}
\hline & Luminosidade $\left(\mathbf{L}^{*}\right)$ \\
\hline & 0 & $52,03 \pm 0,50 \mathrm{cA}$ & $52,03 \pm 0,50 \mathrm{aA}$ \\
\hline$-80{ }^{\circ} \mathrm{C}$ & 120 & $52,28 \pm 0,45 \mathrm{cA}$ & $52,75 \pm 0,22 \mathrm{aA}$ \\
& 180 & $52,19 \pm 0,53 \mathrm{cA}$ & $52,08 \pm 0,37 \mathrm{aA}$ \\
& 240 & $52,85 \pm 1,04 \mathrm{cA}$ & $52,41 \pm 0,45 \mathrm{aA}$ \\
& 300 & $53,52 \pm 0,33 \mathrm{bcA}$ & $52,01 \pm 0,04 \mathrm{aB}$ \\
& 360 & $55,56 \pm 1,85 \mathrm{abA}$ & $53,07 \pm 0,35 \mathrm{aB}$ \\
& 0 & $56,67 \pm 1,82 \mathrm{aA}$ & $53,77 \pm 0,41 \mathrm{aB}$ \\
& 60 & $52,03 \pm 0,50 \mathrm{aA}$ & $52,03 \pm 0,50 \mathrm{aA}$ \\
& 120 & $52,48 \pm 0,47 \mathrm{aA}$ & $52,01 \pm 0,66 \mathrm{aA}$ \\
& 180 & $52,32 \pm 0,54 \mathrm{aA}$ & $52,04 \pm 0,61 \mathrm{aA}$ \\
& 240 & $52,66 \pm 0,48 \mathrm{aA}$ & $52,68 \pm 0,57 \mathrm{aA}$ \\
& 300 & $52,51 \pm 0,28 \mathrm{aA}$ & $52,08 \pm 0,55 \mathrm{aA}$ \\
\hline 30 & $52,44 \pm 0,11 \mathrm{aA}$ & $52,03 \pm 0,55 \mathrm{aA}$ \\
\hline
\end{tabular}

Médias e desvios padrões seguidos de letra igual e minúscula na mesma coluna não diferem significativamente entre si pelo Teste de Tukey a $5 \%$ de probabilidade.

Como L* varia de branco (máximo) a preto (mínimo), pode-se afirmar que todas as amostras ficaram mais claras ao final do armazenamento, mesmo alguns tratamentos não apresentando diferença significativa, como as amostras armazenadas nas temperaturas de $-80^{\circ} \mathrm{C} \mathrm{e}-150{ }^{\circ} \mathrm{C}$, nas embalagens com e sem vácuo.

Em trabalho com lagostins, Rotllant et al. (2002 apud Goméz-Guillén et al., 2005) encontraram valor de luminosidade significativamente superior em camarões rosa Aristeus antennatus tratados com aditivos à base de sulfito, com amostras sem o uso de conservante, demostrando que os sulfitos são potentes agentes redutores e capazes de branquear os crustáceos.

Queiroga et al. (2014), pesquisando a qualidade sensorial do camarão Litopenaeus vannamei congelado, identificou que o parâmetro $L^{*}$ não variou $(\mathrm{p}>0,05)$ entre os tipos de congelamento (freezer doméstico, nitrogênio líquido e túnel), porém aumentou ao longo do tempo, mostrando valores mais altos aos 90 dias de estocagem, tendendo a cores mais claras com tempo de armazenamento.

Tabela 2. Valores médios do parâmetro de intensidade de vermelho ( $\mathrm{a}^{*}$ ) das caudas das lagostas embaladas com e sem vácuo, armazenadas a $-30{ }^{\circ} \mathrm{C},-80^{\circ} \mathrm{C} \mathrm{e}-150{ }^{\circ} \mathrm{C}$, durante 360 dias.

\begin{tabular}{cccc}
\hline & \multicolumn{3}{c}{ Intensidade de vermelho (a*) } \\
\hline \multirow{2}{*}{ Temperatura } & $\begin{array}{c}\text { Armazenamento } \\
\text { (dias) }\end{array}$ & Sem vácuo & Embalagem \\
\cline { 3 - 4 } & 0 & $7,00 \pm 0,14 \mathrm{aA}$ & Com vácuo \\
\hline 60 & $6,55 \pm 0,54 \mathrm{abA}$ & $7,00 \pm 0,14 \mathrm{aA}$ \\
$-30^{\circ} \mathrm{C}$ & 120 & $5,98 \pm 0,12 \mathrm{abA}$ & $6,04 \pm 0,51 \mathrm{abA}$ \\
& 180 & $5,85 \pm 0,95 \mathrm{abA}$ & $5,58 \pm 0,91 \mathrm{abA}$ \\
& 240 & $5,67 \pm 0,72 \mathrm{abA}$ & $5,63 \pm 0,76 \mathrm{abA}$ \\
& 300 & $5,47 \pm 0,25 \mathrm{bA}$ & $5,13 \pm 0,90 \mathrm{bA}$ \\
& 360 & $5,46 \pm 0,24 \mathrm{bA}$ & $4,93 \pm 0,13 \mathrm{bA}$ \\
& & & $4,59 \pm 0,52 \mathrm{bA}$ \\
\hline
\end{tabular}


Tabela 2. Continuação...

\begin{tabular}{cccc}
\hline & Intensidade de vermelho $\left(\mathbf{a}^{*}\right)$ & \\
\hline & 0 & $7,00 \pm 0,14 \mathrm{aA}$ & $7,00 \pm 0,14 \mathrm{aA}$ \\
\hline-80 & $5,68 \pm 0,27 \mathrm{bA}$ & $5,10 \pm 0,34 \mathrm{bA}$ \\
& 120 & $5,47 \pm 0,45 \mathrm{bA}$ & $4,95 \pm 0,16 \mathrm{bA}$ \\
& 180 & $5,06 \pm 0,06 \mathrm{bcA}$ & $5,07 \pm 0,83 \mathrm{bA}$ \\
& 240 & $5,33 \pm 0,18 \mathrm{bA}$ & $5,09 \pm 0,29 \mathrm{bA}$ \\
& 300 & $5,22 \pm 0,39 \mathrm{bcA}$ & $4,95 \pm 0,55 \mathrm{bA}$ \\
& 360 & $4,19 \pm 0,38 \mathrm{cA}$ & $3,71 \pm 0,65 \mathrm{cA}$ \\
& 0 & $7,00 \pm 0,14 \mathrm{aA}$ & $7,00 \pm 0,14 \mathrm{aA}$ \\
\hline 60 & $6,70 \pm 0,90 \mathrm{abA}$ & $6,24 \pm 0,53 \mathrm{abA}$ \\
& 120 & $6,08 \pm 0,33 \mathrm{abcA}$ & $5,40 \pm 0,44 \mathrm{bcA}$ \\
& 180 & $5,35 \pm 0,37 \mathrm{bcA}$ & $4,63 \pm 0,56 \mathrm{cA}$ \\
& 240 & $5,27 \pm 0,88 \mathrm{bcA}$ & $4,57 \pm 0,72 \mathrm{cA}$ \\
\hline 300 & $4,72 \pm 0,86 \mathrm{cA}$ & $4,87 \pm 0,57 \mathrm{bcA}$ \\
\hline
\end{tabular}

Médias e desvios padrões seguidos de letra igual e minúscula na mesma coluna não diferem significativamente entre si pelo Teste de Tukey a $5 \%$ de probabilidade.

Verificou-se uma redução significativa da intensidade de vermelho durante o armazenamento nas três temperaturas estudadas, porém não se verificou o efeito da embalagem de polietileno com e sem vácuo, neste parâmetro.

Carotenoides constituem um grupo numeroso de pigmentos que são responsáveis pelas cores do vermelho ao amarelo em músculos de alguns peixes (salmão e truta) e crustáceos (camarão, lagosta e lagostim) (Uenojo et al., 2007). Em animais, a presença de carotenoides está associada à dieta, pois apenas as plantas superiores, algumas bactérias e leveduras conseguem sintetizar carotenoides (Delgado-Vargas \& Paredes-Lopez, 2003; European Food Safety Authority, 2005). A astaxantina é o carotenoide predominante em crustáceos da ordem Decapoda.

A oxidação da astaxantina deve-se, majoritariamente, à presença de oxigênio, que provoca a quebra de ligações duplas da cadeia poliênica e, consequentemente, a perda de cor e a diminuição das funções biológicas. Outros fatores que estimulam o processo de degradação da astaxantina são a luz, temperaturas superiores a $40{ }^{\circ} \mathrm{C}$ e o contato com ácidos, bases e metais (Zavaleta, 2010).

A redução da intensidade de vermelho foi decorrente da instabilidade da astaxantina, havendo a necessidade de investigar formas de proteger a estabilidade desta molécula e, portanto, as suas funções biológicas (Kittikaiwan et al., 2002). Uma opção é o uso de embalagem de alta barreira ao oxigênio associada ao acondicionamento a vácuo. 
Tabela 3. Valores médios do parâmetro de intensidade de amarelo $\left(+b^{*}\right)$ das caudas das lagostas embaladas com vácuo e sem vácuo, e armazenadas a $-30{ }^{\circ} \mathrm{C},-80{ }^{\circ} \mathrm{C}$ e $-150{ }^{\circ} \mathrm{C}$, durante 360 dias.

\begin{tabular}{|c|c|c|c|}
\hline \multicolumn{4}{|c|}{ Intensidade de amarelo $\left(b^{*}\right)$} \\
\hline \multirow{2}{*}{ Temperatura } & \multirow{2}{*}{$\begin{array}{c}\text { Tempo de Armazenamento } \\
\text { (dias) }\end{array}$} & \multicolumn{2}{|c|}{ Embalagem } \\
\hline & & Sem vácuo & Com vácuo \\
\hline \multirow{7}{*}{$-30{ }^{\circ} \mathrm{C}$} & 0 & $10,66 \pm 0,89 \mathrm{bA}$ & $10,66 \pm 0,89 \mathrm{aA}$ \\
\hline & 60 & $11,30 \pm 0,74 \mathrm{abA}$ & $11,130 \pm 0,09 \mathrm{aA}$ \\
\hline & 120 & $11,00 \pm 0,71 \mathrm{bA}$ & $12,03 \pm 0,85 \mathrm{aA}$ \\
\hline & 180 & $11,20 \pm 0,10 \mathrm{abA}$ & $11,90 \pm 0,27 \mathrm{aA}$ \\
\hline & 240 & $11,49 \pm 0,07 \mathrm{abA}$ & $11,79 \pm 0,63 \mathrm{aA}$ \\
\hline & 300 & $12,14 \pm 1,48 \mathrm{abA}$ & $12,03 \pm 0,14 \mathrm{aA}$ \\
\hline & 360 & $12,86 \pm 0,25 \mathrm{aA}$ & $12,26 \pm 0,61 \mathrm{aA}$ \\
\hline \multirow{7}{*}{$-80^{\circ} \mathrm{C}$} & 0 & $10,66 \pm 0,89 \mathrm{bA}$ & $10,66 \pm 0,89 \mathrm{aA}$ \\
\hline & 60 & $11,32 \pm 0,61 \mathrm{abA}$ & $10,88 \pm 0,48 \mathrm{aA}$ \\
\hline & 120 & $12,07 \pm 0,35 \mathrm{abA}$ & $11,28 \pm 0,18 \mathrm{aA}$ \\
\hline & 180 & $12,25 \pm 0,46 \mathrm{abA}$ & $11,67 \pm 1,71 \mathrm{aA}$ \\
\hline & 240 & $12,72 \pm 0,57 \mathrm{aA}$ & $12,49 \pm 0,38 \mathrm{aA}$ \\
\hline & 300 & $12,66 \pm 1,21 \mathrm{aA}$ & $12,38 \pm 0,52 \mathrm{aA}$ \\
\hline & 360 & $12,78 \pm 0,42 \mathrm{aA}$ & $12,36 \pm 0,11 \mathrm{aA}$ \\
\hline \multirow{7}{*}{$-150^{\circ} \mathrm{C}$} & 0 & $10,66 \pm 0,89 \mathrm{aA}$ & $10,66 \pm 0,89 \mathrm{aA}$ \\
\hline & 60 & $10,48 \pm 0,51 \mathrm{aA}$ & $10,27 \pm 1,29 \mathrm{aA}$ \\
\hline & 120 & $10,35 \pm 0,45 \mathrm{aA}$ & $10,56 \pm 1,14 \mathrm{aA}$ \\
\hline & 180 & $10,48 \pm 0,84 \mathrm{aA}$ & $11,07 \pm 0,90 \mathrm{aA}$ \\
\hline & 240 & $11,48 \pm 0,51 \mathrm{aA}$ & $11,61 \pm 0,87 \mathrm{aA}$ \\
\hline & 300 & $11,38 \pm 1,89 \mathrm{aA}$ & $11,09 \pm 0,73 \mathrm{aA}$ \\
\hline & 360 & $12,01 \pm 1,52 \mathrm{aA}$ & $11,26 \pm 1,36 \mathrm{aA}$ \\
\hline
\end{tabular}

Médias e desvios padrões seguidos de letra igual e minúscula na mesma coluna não diferem significativamente entre si pelo Teste de Tukey a $5 \%$ de probabilidade.

Para o parâmetro intensidade de amarelo $\left(\mathrm{b}^{*}\right)$, as amostras embaladas sem vácuo nas temperaturas de $30{ }^{\circ} \mathrm{C}$ e $-80{ }^{\circ} \mathrm{C}$ apresentaram um aumento significativo. Já as demais amostras não apresentaram diferença significativa entre os tratamentos analisados.

Nas Tabelas 4 e 5, são apresentados os valores médios de proteína total das caudas de lagosta embaladas a vácuo e sem vácuo, e armazenadas em diferentes temperaturas de congelamento. 
Tabela 4. Valores médios da proteína (\%) das caudas das lagostas embaladas a vácuo e sem vácuo, armazenadas a $30{ }^{\circ} \mathrm{C},-80{ }^{\circ} \mathrm{C}$ e $-150{ }^{\circ} \mathrm{C}$, durante 360 dias.

\begin{tabular}{|c|c|c|c|}
\hline \multicolumn{4}{|c|}{ Proteína total (\%) } \\
\hline \multirow{2}{*}{ Temperatura } & \multirow{2}{*}{$\begin{array}{c}\text { Tempo de } \\
\text { Armazenamento } \\
\text { (dias) }\end{array}$} & \multicolumn{2}{|c|}{ Embalagem } \\
\hline & & Sem vácuo & Com vácuo \\
\hline \multirow{7}{*}{$-30^{\circ} \mathrm{C}$} & 0 & $17,50 \pm 0,25 \mathrm{aA}$ & $17,50 \pm 0,25 \mathrm{aA}$ \\
\hline & 60 & $15,64 \pm 0,64 \mathrm{bcA}$ & $14,45 \pm 0,80 \mathrm{cB}$ \\
\hline & 120 & $16,49 \pm 0,97 \mathrm{abA}$ & $14,87 \pm 1,05 \mathrm{bcA}$ \\
\hline & 180 & $14,98 \pm 0,98 \mathrm{cdA}$ & $15,19 \pm 0,30 \mathrm{bcA}$ \\
\hline & 240 & $14,77 \pm 1,56 \mathrm{cdB}$ & $17,45 \pm 0,65 \mathrm{aA}$ \\
\hline & 300 & $14,57 \pm 0,69 \mathrm{cdA}$ & $14,79 \pm 0,65 \mathrm{cA}$ \\
\hline & 360 & $14,54 \pm 0,19 \mathrm{dA}$ & $15,92 \pm 0,84 \mathrm{bA}$ \\
\hline \multirow{7}{*}{$-80^{\circ} \mathrm{C}$} & 0 & $17,50 \pm 0,25 \mathrm{aA}$ & $17,50 \pm 0,25 \mathrm{aA}$ \\
\hline & 60 & $14,06 \pm 0,19 \mathrm{bA}$ & $14,68 \pm 0,21 \mathrm{cdA}$ \\
\hline & 120 & $14,61 \pm 0,90 \mathrm{bB}$ & $16,46 \pm 0,23 \mathrm{abA}$ \\
\hline & 180 & $14,98 \pm 0,41 \mathrm{bA}$ & $15,19 \pm 0,30 \mathrm{bcdA}$ \\
\hline & 240 & $16,57 \pm 0,14 \mathrm{aA}$ & $13,94 \pm 0,42 \mathrm{~dB}$ \\
\hline & 300 & $16,93 \pm 0,53 \mathrm{aA}$ & $15,40 \pm 0,43 \mathrm{bcB}$ \\
\hline & 360 & $14,41 \pm 0,55 \mathrm{bB}$ & $15,35 \pm 0,30 \mathrm{bcA}$ \\
\hline \multirow{7}{*}{$-150^{\circ} \mathrm{C}$} & 0 & $17,50 \pm 0,25 \mathrm{aA}$ & $17,50 \pm 0,25 \mathrm{aA}$ \\
\hline & 60 & $14,53 \pm 0,25 \mathrm{cdA}$ & $14,96 \pm 0,08 \mathrm{cA}$ \\
\hline & 120 & $14,60 \pm 0,08 \mathrm{cdB}$ & $16,17 \pm 0,56 \mathrm{bA}$ \\
\hline & 180 & $14,43 \pm 0,31 \mathrm{cdA}$ & $15,09 \pm 0,40 \mathrm{bcA}$ \\
\hline & 240 & $14,63 \pm 0,28 \mathrm{cdA}$ & $14,42 \pm 0,45 \mathrm{cA}$ \\
\hline & 300 & $16,59 \pm 0,46 \mathrm{abA}$ & $14,98 \pm 0,49 \mathrm{cB}$ \\
\hline & 360 & $15,66 \pm 0,30 \mathrm{bcA}$ & $15,38 \pm 0,87 \mathrm{bcA}$ \\
\hline
\end{tabular}

Médias e desvios padrões seguidos de letra igual e minúscula na mesma coluna não diferem significativamente entre si pelo Teste de Tukey a $5 \%$ de probabilidade.

Ocorreu uma redução significativa do teor de proteínas, ao longo do tempo, nas três temperaturas de armazenamento. Verificou-se na embalagem sem vácuo, na temperatura de $-80^{\circ} \mathrm{C}$, uma redução significativa já nos primeiros 60 dias, permanecendo estável até os 180 dias e voltando a apresentar o mesmo valor, no final dos 360 dias de armazenamento; observou-se, também, que as caudas de lagostas embaladas a vácuo e mantidas a $-30^{\circ} \mathrm{C}$ foram as que melhor conservaram o teor de proteína.

Mira \& Lanfer-Marquez (2005) encontraram, em seu trabalho com surimi, um aumento nos teores de proteína de $9 \%$ para 16\%, ao final dos 360 dias de armazenamento, comportamento oposto ao encontrado neste trabalho. Possivelmente, esta redução pode ter ocorrido devido à ausência de crioprotetores, que são ingredientes capazes de prevenir o crescimento dos cristais de gelo e a migração de moléculas de água das proteínas, estabilizando-as em sua forma natural (MacDonald \& Lanier, 1997).

Ocorrem interações bioquímicas na estocagem congelada prolongada entre as proteínas e os ácidos graxos do músculo de pescado. O congelamento resulta em lise das enzimas da mitocôndria e dos lisossomos, com 
consequente alteração na distribuição das enzimas e declínio gradual das suas atividades; note-se que há perda das propriedades funcionais das proteínas. O glazeamento e a embalagem a vácuo amenizam ou mesmo controlam o problema (Sikorski \& Kotakowska, 1994).

Na Tabela 5, são apresentados os valores médios de lipídeo total das caudas de lagosta embaladas a vácuo e sem vácuo, e armazenadas em diferentes temperaturas de congelamento.

Tabela 5. Valores médios do lipídeo (\%) das caudas das lagostas embaladas com vácuo e sem vácuo, armazenadas a $30{ }^{\circ} \mathrm{C},-80{ }^{\circ} \mathrm{C}$ e $-150{ }^{\circ} \mathrm{C}$, durante 360 dias.

\begin{tabular}{|c|c|c|c|}
\hline \multicolumn{4}{|c|}{ Lipídeo (\%) } \\
\hline \multirow{2}{*}{ Temperatura } & \multirow{2}{*}{$\begin{array}{c}\text { Tempo de } \\
\text { Armazenamento } \\
\text { (dias) }\end{array}$} & \multicolumn{2}{|c|}{ Embalagem } \\
\hline & & Sem vácuo & Com vácuo \\
\hline \multirow{7}{*}{$-30^{\circ} \mathrm{C}$} & 0 & $0,19 \pm 0,03 \mathrm{abA}$ & $0,19 \pm 0,03 \mathrm{bcA}$ \\
\hline & 60 & $0,18 \pm 0,01 \mathrm{bB}$ & $0,30 \pm 0,01 \mathrm{aA}$ \\
\hline & 120 & $0,29 \pm 0,03 \mathrm{aA}$ & $0,14 \pm 0,02 \mathrm{cB}$ \\
\hline & 180 & $0,18 \pm 0,02 \mathrm{bA}$ & $0,17 \pm 0,01 \mathrm{bcA}$ \\
\hline & 240 & $0,26 \pm 0,02 \mathrm{abA}$ & $0,17 \pm 0,02 \mathrm{bcB}$ \\
\hline & 300 & $0,19 \pm 0,01 \mathrm{abA}$ & $0,19 \pm 0,01 \mathrm{bcA}$ \\
\hline & 360 & $0,25 \pm 0,01 \mathrm{abA}$ & $0,26 \pm 0,02 \mathrm{abA}$ \\
\hline \multirow{7}{*}{$-80^{\circ} \mathrm{C}$} & 0 & $0,19 \pm 0,03 a b c A$ & $0,19 \pm 0,03 \mathrm{cA}$ \\
\hline & 60 & $0,28 \pm 0,02 \mathrm{aA}$ & $0,19 \pm 0,01 \mathrm{cB}$ \\
\hline & 120 & $0,22 \pm 0,02 \mathrm{abcA}$ & $0,23 \pm 0,01 \mathrm{bcA}$ \\
\hline & 180 & $0,26 \pm 0,01 \mathrm{abA}$ & $0,32 \pm 0,02 \mathrm{abA}$ \\
\hline & 240 & $0,14 \pm 0,04 \mathrm{cdB}$ & $0,28 \pm 0,02 \mathrm{bcA}$ \\
\hline & 300 & $0,04 \pm 0,01 \mathrm{dA}$ & $0,04 \pm 0,01 \mathrm{dA}$ \\
\hline & 360 & $0,17 \pm 0,01 \mathrm{bcB}$ & $0,20 \pm 0,02 \mathrm{cA}$ \\
\hline \multirow{7}{*}{$-150^{\circ} \mathrm{C}$} & 0 & $0,19 \pm 0,03 \mathrm{bcA}$ & $0,19 \pm 0,03 \mathrm{bcA}$ \\
\hline & 60 & $0,35 \pm 0,01 \mathrm{aA}$ & $0,31 \pm 0,01 \mathrm{aA}$ \\
\hline & 120 & $0,26 \pm 0,02 \mathrm{abcA}$ & $0,19 \pm 0,02 \mathrm{bcB}$ \\
\hline & 180 & $0,20 \pm 0,02 \mathrm{bcB}$ & $0,28 \pm 0,03 \mathrm{abA}$ \\
\hline & 240 & $0,16 \pm 0,01 \mathrm{cA}$ & $0,13 \pm 0,02 \mathrm{cdA}$ \\
\hline & 300 & $0,06 \pm 0,0 \mathrm{dA}$ & $0,06 \pm 0,02 \mathrm{dA}$ \\
\hline & 360 & $0,27 \pm 0,01 \mathrm{abB}$ & $0,15 \pm 0,0 \mathrm{cA}$ \\
\hline
\end{tabular}

Médias e desvios padrões seguidos de letra igual e minúscula na mesma coluna não diferem significativamente entre si pelo Teste de Tukey a $5 \%$ de probabilidade.

Verificou-se, no armazenamento a $-80^{\circ} \mathrm{C}$ e a $-150{ }^{\circ} \mathrm{C}$, que, aos 300 dias, o produto apresentou os menores teores de lipídeos em ambas as embalagens, contudo não se verificou uma tendência crescente ou decrescente ao longo do tempo de armazenamento. 


\section{Conclusão}

Verificou-se redução nos valores proteicos porém, os lipídeos se mantiveram sem alterações significativas durante o armazenamento. A luminosidade $\left(\mathrm{L}^{*}\right)$ das caudas das lagostas aumentou nas temperaturas de $30{ }^{\circ} \mathrm{C}$ e $-80{ }^{\circ} \mathrm{C}$, na embalagem sem vácuo. Nos demais tratamentos, não houve diferença significativa ao longo do armazenamento. A intensidade de vermelho ( $\left.\mathrm{a}^{*}\right)$ diminuiu em todos os tratamentos. A intensidade de amarelo $\left(b^{*}\right)$ aumentou nas temperaturas de $-30{ }^{\circ} \mathrm{C}$ e $-80{ }^{\circ} \mathrm{C}$ sem vácuo. Em relação às temperaturas de armazenamento estudadas, a proteína e intensidade de amarelo tiveram maior redução à $-30^{\circ} \mathrm{C}$; para lipídeos, luminosidade e intensidade de amarelo não houve diferença significativa. $\mathrm{O}$ efeito das embalagens com e sem vácuo na manutenção dos constituintes físicos e químicos não apresentou tendência crescente ou decrescente ao longo do tempo de armazenamento.

\section{Referências}

Brasil. Ministério do Desenvolvimento, Indústria e Comércio Exterior - MDIC. Sistema AliceWeb [Internet]. 2013. Recuperado em 16 de abril de 2013, de http://aliceweb.desenvolvimento.gov.br/

Delgado-Vargas, F., \& Paredes-Lopez, O. (2003). Natural colorants for food and nutraceutical uses. Florida: CRC Press.

European Food Safety Authority - EFSA. (2005). Opinion of the scientific panel on additives and products or substances used in animal feed on the request from the European Commission on the safety of use of colouring agents in animal nutrition: Part 1. General principles and Astaxanthin (Question No. EFSA-2003-060). The EFSA Journal, 291, 1-40.

Food and Agriculture Organization of the United Nations - FAO. (2014). Fishers and aquaculture statistic: global capture production 1950-2012. Rome: FAO Fishers and Aquaculture Department.

Goméz-Guillén, M. C., Giménez, B., \& Montero, P. (2005). Extracion of gelatina from fish skins by high pressure treatment. Food Hidrocoloid, 19(5), 923-928. https://doi.org/10.1016/j.foodhyd.2004.12.011.

Igarashi, M. A. (2007). Sinopse da situação atual, perspectivas e condições de cultivo para lagostas Palinuridae. Ciência Animal Brasileira, 8(2), 151-166.

Instituto Adolfo Lutz - IAL. (2008). Métodos físico-químicos para análise de alimentos (4. ed., 1020 p.). São Paulo: IAL. Primeira edição digital.

Kittikaiwan, P., Powthongsook, S., Pavasant, P., \& Shotipruk, A. (2002). Encapsulation of Haematococcus pluvialis using chitosan for astaxanthin stability enhancement. Carbohydrate Polymers, 70(4), 378-385. https://doi.org/10.1016/j.carbpol.2007.04.021

MacDonald, G. A., \& Lanier, T. C. (1997). Cryoprotectantes for improving frozen food quality. In M. C. Ericson \& Y. C. Hung Quality in frozen foods (pp. 197-232). Nova lorque: International Thompson Publishing.

Mira, N. V. M., \& Lanfer-Marquez, U. M. (2005). Avaliação da composição centesimal, aminoácidos e mercúrio contaminante do surimi. Ciência e Tecnologia de Alimentos, 425(4), 665-671. http://dx.doi.org/10.1590/S0101-20612005000400007

Queiroga, I. M. B. N., Silva, J. A., Cavalheiro, J. M. O., Queiroga, R. C. R. E., Batista, A. S. M., \& Barreto, T. A. (2014).

Qualidade sensorial do camarão Litopenaeusvannameii congelado. Semina Ciências Agrárias, 35(4), 1801-1812. http://dx.doi.org/10.5433/1679-0359.2014v35n4p1801

Sikorski, Z. E., \& Kotakowska, A. (1994). Changes in proteins in frozen stored fish. In Z. E. Sikorski, B. Sun Pan \& F. Shahidi. Seafood protein (pp. 99-112). Nova lorque: Chapman \& Hall. http://dx.doi.org/10.1007/978-1-4615-7828-4_8.

Silva, F. A. S., \& Azevedo, C. A. V. (2009). Principal components analysis in the software assistat-statistical attendance. In Proceedings of the 7th World Congress on Computers in Agriculture. St. Joseph: American Society of Agricultural and Biological Engineers.

Uenojo, M., Maróstica Junior, M. R., \& Pastore, G. M. (2007).Carotenóides: propriedades, aplicações e biotransformação param formação de compostos de aroma. Química Nova, 30(3), 3. http://dx.doi.org/10.1590/S0100-40422007000300022

Zavaleta, M. F. (2010). Extracción de astaxantina a partir de residuos de camarón ensilados por métodos ácido y bacteriano (Tese de doutorado). México: Universidad Autónoma Metropolitana-Iztapalapa, Division de Ciencias Biologicas. 